\title{
Centrifuge modelling of offshore monopile foundation
}

\author{
Klinkvort, Rasmus Tofte; Hededal, Ole
}

Published in:

Frontiers in Offshore Geotechnics II

Publication date:

2010

Document Version

Publisher's PDF, also known as Version of record

Link back to DTU Orbit

Citation (APA):

Klinkvort, R. T., \& Hededal, O. (2010). Centrifuge modelling of offshore monopile foundation. In Frontiers in Offshore Geotechnics // (1 ed., pp. 581-586). Taylor \& Francis.

\section{General rights}

Copyright and moral rights for the publications made accessible in the public portal are retained by the authors and/or other copyright owners and it is a condition of accessing publications that users recognise and abide by the legal requirements associated with these rights.

- Users may download and print one copy of any publication from the public portal for the purpose of private study or research.

- You may not further distribute the material or use it for any profit-making activity or commercial gain

- You may freely distribute the URL identifying the publication in the public portal

If you believe that this document breaches copyright please contact us providing details, and we will remove access to the work immediately and investigate your claim. 


\title{
Centrifuge modelling of offshore monopile foundation
}

\author{
R.T. Klinkvort \& O. Hededal \\ Technical University of Denmark, Copenhagen, Denmark
}

\begin{abstract}
Today one of the most used concepts for wind turbine foundation is the monopile. The foundation concepts for these monopiles on deeper water is uncertain and consequently the design needs to be conservative leading to uneconomic designs. This paper describes a total number of 6 static and 5 cyclic centrifuge tests on a laterally loaded monopile in dry sand. The prototype dimension of the piles was modelled to a diameter of 1 meter and penetration depth on 6 meter. The test series were designed in order to investigate the scaling laws in the centrifuge both for monotonic and cyclic loading. It was not possible in the tests to reproduce the same prototype response for both the monotonic and the cyclic loading. It was not clear if this scatter in prototype data was due to normal measurement uncertainties or if the response is depending on the scaling factor.
\end{abstract}

\section{INTRODUCTION}

Single large diameter tubular steel piles commonly denoted monopiles is today a very used foundation method for offshore wind turbines. The design of these monopiles is commonly based on the theory of laterally loaded piles which relies on empirical data originated from the oil and gas industry, Reese and Matlock (1956) \& McClelland and Focht (1958). The lateral capacity is determined by modelling the pile as a beam and the soil as a system of uncoupled springs, this is known as aWinkler model. The springs are described by $p-y$ curves defining the load-displacement relationship for the interaction between soil and pile, API (1993). The formulation of these curves was originally calibrated to slender piles, but is today even used for design of large diameter monopiles with a slenderness ratio $L / D$ as low as 5 . The monopiles used for wind turbine foundations thus act as stiff piles. Therefore it is relevant to investigate the behavior of stiff piles in more detail. The tests series presented in this paper is an initial program that intends to investigate the response of model monopiles subjected to different artificial gravities in a centrifuge. The concept called modelling of models is used to investigate the response from five different piles which are scaled to the same prototype dimensions.

\section{CENTRIFUGE MODELLING}

When performing centrifuge tests an artificial gravity is applied to a model test setup. This is done to ensure that the stress field in the model is similar to the stress field in the prototype. This is important in model testing due to the non-linearity of the stressstrain relations of soils. To apply the artificial gravity the model is placed at the end of a rotating arm. The acceleration in a specified point in the model is given by the angular rotation speed $(\omega)$ and the distance $(R)$ from the rotational axis. The ratio between gravity $(g)$ and artificial gravity is described by the gravity scale factor $(N)$.

$N=R \omega^{2} / g$

In centrifuge modelling two key issues are represented, the scaling laws and the scaling errors.

\subsection{Scaling laws}

To transform results from test carried out on models to prototypes the dimensional analysis can be used, Langhaar (1951). The foundation for the dimensional analysis is Buckingham's $\Pi$ theorem. From this, dimensionless parameters can be determined. These dimensionless parameters have to be the same for the prototype and the model to have full similarity. If all governing laws of similitude are in place a true model is obtained. This implies that stresses and strains are scaled by a factor of 1 , deflection and lengths is scaled by a factor of $N$, forces are scaled by a factor of $N^{2}$ and so on; see e.g. Taylor (1995).

\subsection{Scale effects}

In physical modelling it is seldom possible to produce a model where all details of the model is scaled correctly in the prototype. Therefore some approximations have to be made. These differences are called scale effects and are important to be aware of when the test results are interpreted. Model studies are not perfect and it is important to understand this. Two main effects will be presented here. The first is the stress distribution. Looking at Equation 1 on the preceding page it can be seen that the applied gravity is depending on the distance to the rotational axis. 

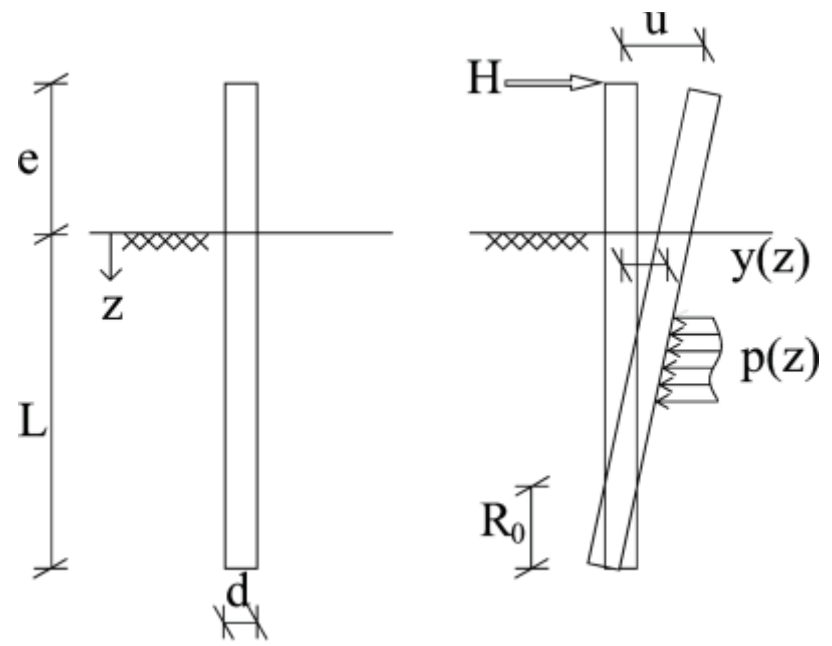

Figure 1. Sketch of pile.

This distance will increase through the model. In the prototype the stresses will increase linearly due to the constant gravity field, whereas the stresses in the model will increase parabolically. To minimize this error the radius is defined from center to a depth of 2/3 of the pile penetration depth, Stuit (1995).

When performing centrifuge modelling it is not possible to scale the sand grain diameter correctly, since this will imply a difference in friction angle and cohesion. Therefore, when considering bearing capacity, it is most often necessary to use the same sand in the model as in the prototype. This causes the sand grains to be scaled by a factor of $\mathrm{N}$ in the model. This is known as the particle size effect. The grain size effect has been investigated with "modelling of models". Particle size effect has been tested for laterally loaded piles by Hoadley et al. (1981) and they found that a "model diameter/ grain size diameter" ratio of 50 and above gave a good agreement. Remaud et al. (1998) found that a ratio over 60 was enough to avoid particle size effects. Both of these studies were performed on long slender piles. Nunez et al. (1988) performed modelling of models on tension piles. They found that the smaller piles tested at high accelerations gave consistently higher capacity than larger piles tested at smaller accelerations. They explain this difference with installation effects and differences in wall thickness and conclude that the effect from particle size is not significant.

\section{EXPERIMENTS}

As the first of a larger test series on monopiles a series of modelling of models have been performed to analyze the response of a monopile in relation to the applied gravity. The test program was performed on five solid steel piles with a diameter between 16$40 \mathrm{~mm}$ and penetration depths between $96-240 \mathrm{~mm}$ which were all scaled to a prototype pile with a diameter of $d=1 \mathrm{~m}$ and penetration depth $L=6 \mathrm{~m}$.

In figure 1 a sketch of the test pile can be seen. In Table 1 the dimension of the five piles and the scaling
Table 1. Dimensions and scaling factor for the piles.

\begin{tabular}{llll}
\hline$d$ & $e$ & $L$ & $N$ \\
{$[\mathrm{~mm}]$} & {$[\mathrm{mm}]$} & $\begin{array}{l}L \\
{[\mathrm{~mm}]}\end{array}$ & \begin{tabular}{l}
\multicolumn{1}{c}{$[-]$} \\
16
\end{tabular} \\
\hline 22 & 40 & 96 & 62.5 \\
28 & 55 & 132 & 45.5 \\
34 & 70 & 168 & 35.7 \\
40 & 85 & 204 & 29.4 \\
\hline
\end{tabular}

Table 2. Classification parameters for the Fontainebleau sand.

\begin{tabular}{lll}
\hline Specific gravity of particles & $G_{s}$ & 2.646 \\
Minimum void ratio & $e_{\min }$ & 0.548 \\
Maximum void ratio & $e_{\max }$ & 0.859 \\
Average grain size & $d_{50}$ & 0.18 \\
Coefficient of uniformity & $C_{u}$ & 1.6 \\
\hline
\end{tabular}

Table 3. Void ratio for the different tests.

\begin{tabular}{llllll}
\hline $\mathrm{d}[\mathrm{mm}]$ & 16 & 22 & 28 & 34 & 40 \\
\hline Monotonic & $0.58 / 0.57$ & 0.58 & 0.57 & 0.59 & 0.56 \\
Cyclic & 0.59 & 0.56 & 0.56 & 0.58 & 0.55 \\
\hline
\end{tabular}

factor is shown. This should scale all the piles to the same prototype pile.

All monotonic and cyclic tests were performed in dry Fontainebleau sand. Leth et al. (2008) has collected classification parameters for the Fontainebleau sand which can be seen in table 2 on the next page. The average grain size of the Fontainebleau sand is $0.18 \mathrm{~mm}$. With pile diameter ranging from $16 \mathrm{~mm}$ to $40 \mathrm{~mm}$ this leads to a "model diameter/ grain size diameter" ratio ranging from 88 to 189 .

The centrifuge at DTU uses a spot pouring hopper (SPH) for the preparation of the sand sample. Due to the geometry of the container and pile the sand is prepared using a circular travelling loop as described in Zhao et al. (2006). The sand is installed in a container with a inner diameter of $50 \mathrm{~cm}$ and a height of $49 \mathrm{~cm}$. A new sample is prepared for each of the tests. CPT tests have been carried out to validate the pouring method. All these CPT tests showed the soil sample has a good homogeneity in the container.

After the sand is prepared, the pile is installed at $1 \mathrm{~g}$. It must be expected that the sand is compacted in a higher degree around the pile, for large piles than for small piles. When the tests are carried out it must be expected that the stresses in the sand is so high that potential preconsolidated areas disappears. Installing the pile at $1 \mathrm{~g}$. is therefore intended to minimize the effects from the installation.

A total of 11 centrifuge tests have been performed: six monotonic and five cyclic. For all the tests the relative density was found to vary in the range $0.8-0.94$. A table with the different void ratios can be seen in table 3 on the following page. The relative densities 


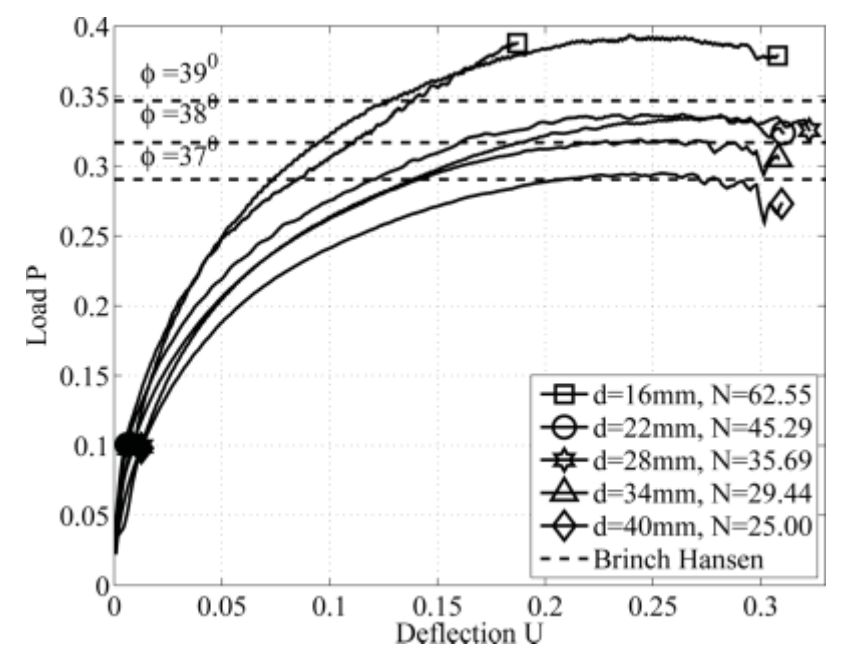

Figure 2. Normalized plot with the five static tests.

are calculated by knowing the weight and the volume of the sand sample. The average value for both the static and cyclic tests is for the relative density $I_{D}=0.924$ and a void ratio of $e=0.57$ leading to a triaxial frictional angle of $\phi=38^{\circ}$.

\subsection{Monotonic tests}

The force and deflection is normalized, to compare the general pile behavior. On the y-axis the normalized force is plotted. This is found as shown in equation 2 .

$P=\frac{H}{\gamma \cdot L^{3}}$

On the $\mathrm{x}$-axis the normalized deflection is plotted. This is shown in equation 3

$U=\frac{u}{L}$

In figure 2 the observation of the monotonic loading can be seen. Remember that all the test is scaled to same prototype and the response from the different tests should be identical. However a variation in the results can be seen. The test performed at $62.5 \mathrm{~g}$ showed a significantly high bearing capacity therefore a second test on the $d=16 \mathrm{~mm}$ was performed to validate the response. The second test confirmed the response.

Interpretation method 1: Looking at figure 2 you could say that the pile with a diameter of $d=16 \mathrm{~mm}$ shows a much higher capacity than the other piles and thereby indicates that the pile diameter particle diameter is too small. If this pile is neglected an acceptable scatter of the results is obtained. From this a bearing capacity for the prototype pile could be expected to be $P_{\max } \approx 0.32$. This will be called interpretation method 1 . On figure 2 the bearing capacity according to Hansen (1961) is shown for three different frictional angles. This indicates small change in frictional angle can be the reason for this scatter. On the other hand using the result from the pile with a diameter of
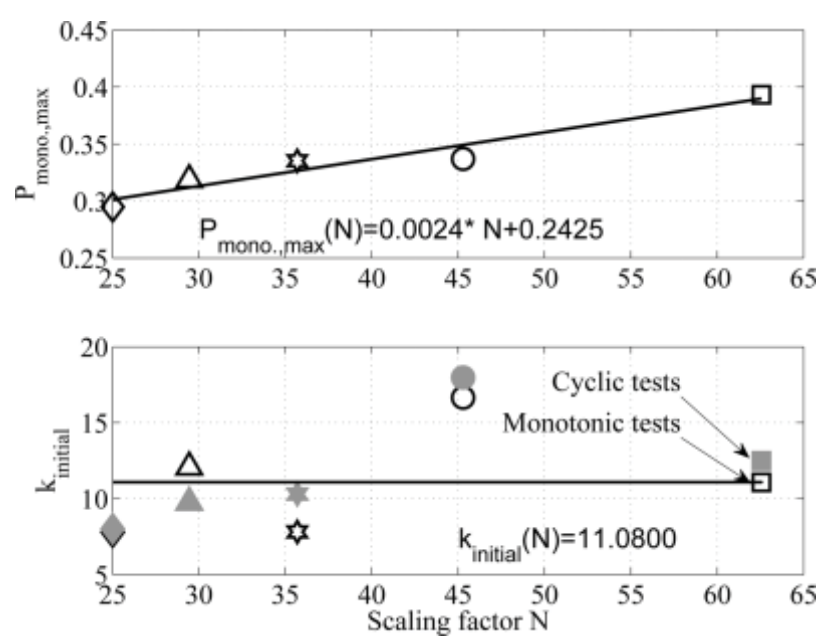

Figure 3. Normalized plot bearing capacity and initial stiffness as a function of the scaling factor.

$d=16 \mathrm{~mm}$ it can be seen that the maximum bearing capacity is increasing with the applied gravity. This could indicate that the linear scaling which is assumed is problematic.

Interpretation method 2: The maximum bearing capacity and the initial stiffness is plotted on figure 3 against the scaling factor. The maximum capacity is found as the maximum value found on figure 2 and the initial stiffness is found at the point where the applied load is $P=0.1$. This is shown on figure 2 as the black markings. From figure 3 it seems to be a clear linear relationship between the maximum bearing capacity and the scaling factor. Looking at the initial stiffness of the load deflection response no clear relationship is seen. The variance of the stiffness could though indicate that a constant stiffness from the tests could be expected. Here is also plotted the initial stiffness found from the cyclic testing which support this conclusion.

Four of the piles were mounted with measuring of the pile head rotation, if the pile is assumed to behave as a rigid pile, the pile movement can be described according to equation 4 .

$y(z)=u-\theta(e+z)$

The assumption of the pile behaves like a rigid pile is satisfied according to Poulos and Hull (1989) if the stiffness of the sand is lesser than $E_{s}=35 \mathrm{MPa}$. If the pile should act as a slender pile then the soil stiffness should be over $E_{s}=3090 \mathrm{MPa}$. Even if the stiffness of the sand is larger than $35 \mathrm{MPa}$ it is expected that the pile will be located close to the rigid boundary. Therefore it is assumed that the pile behaves as a stiff pile. From this assumption the point of rotation can be found knowing the deflection of the pile $u$ and the rotation $\theta$. The normalize point of rotation measured from pile tip is plotted in figure 4. Due to practical reasons the rotation of the $16 \mathrm{~mm}$ pile could not be measured. All the piles shows that the normalized point of rotation is located below the pile tip at initial deflection and the pile is therefore sheared through the sand. After some deformation the rotation point moves up and is located 


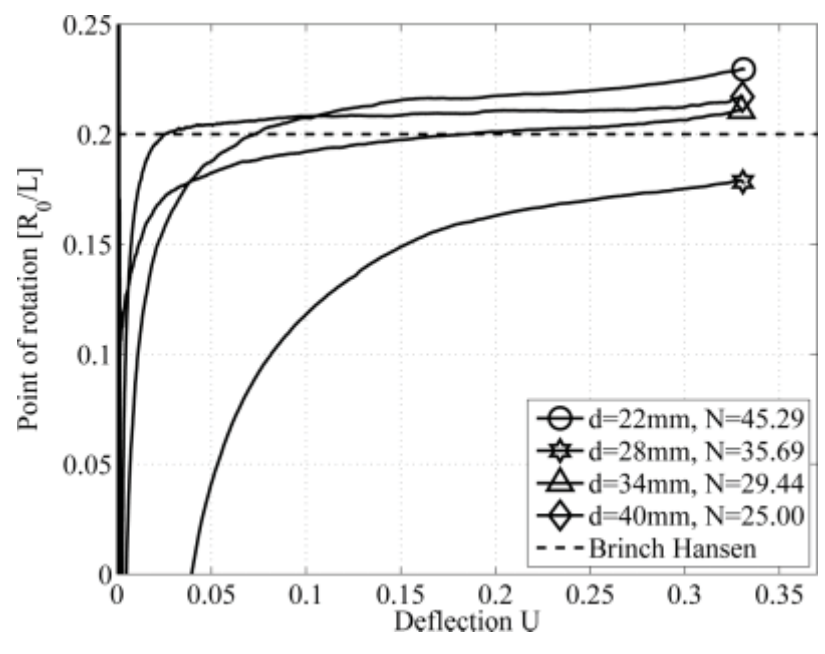

Figure 4. Point of rotation.

in the pile where it is stabilized until failure. From figure 4 no clear relation between normalized point of rotation and scaling factor can be seen. It seems like for all the piles that the rotation point stabilizes around a value of 0.22 except the pile with a diameter of $d=28 \mathrm{~mm}$ which haves a lower rotation point that the others. Using the theory of Hansen (1961) the rotation point is calculated to 0.2 which is close to the observation. It seems like all the piles is moving in the same manner.

\subsection{Cyclic tests}

The cyclic tests were performed with 500 force controlled cycles. To investigate the effects from cyclic loading this paper uses a method describe in LeBlanc (2009) to described the cyclic loading. The load characteristics are denoted $\zeta_{b}$ and $\zeta_{c}$. They are determined as shown in equation 5 .

$\zeta_{b}=\frac{P_{\max }}{P_{\text {monotonic }}} \quad \zeta_{c}=\frac{P_{\min }}{P_{\max }}$

Here $P_{\max }$ and $P_{\min }$ are the maximum and minimum applied force in the cyclic loading. $\mathrm{P}_{\text {monotonic }}$ is the maximum bearing capacity found from the corresponding monotonic test.

The amount of the applied load depends on the interpretation of the monotonic test. The cyclic loading was performed as individual tests, with five different maximum capacities according to the monotonic tests shown on figure 2 on the preceding page. It was the intension to perform the cyclic test with a $\zeta_{b}=0.40$ and a $\zeta_{c}=0$ but due to the control system it has not been possible to perform tests with exactly the same load characteristics. However the load characteristics can also be calculated assuming a constant bearing capacity for the monotonic tests. The characteristics of the cyclic loading for the tests series for the two types of interpretation can be seen on Figure 4. For the cyclic loading the accumulation of deflection and the change in secant stiffness is calculated. This is done as showed on figure 5. For every cycle the maximum and
Table 4. Load characteristics for the cyclic tests.

\begin{tabular}{llllll}
\hline$N$ & $P_{\text {mono., } 1}$ & $P_{\text {mono., }}$ & $\zeta_{b, 1}$ & $\zeta_{b, 2}$ & $\zeta_{c}$ \\
\hline 62.6 & 0.32 & 0.39 & 0.53 & 0.44 & -0.04 \\
45.3 & 0.32 & 0.34 & 0.52 & 0.49 & -0.05 \\
35.7 & 0.32 & 0.34 & 0.44 & 0.44 & -0.02 \\
29.4 & 0.32 & 0.32 & 0.41 & 0.42 & -0.02 \\
25.0 & 0.32 & 0.29 & 0.41 & 0.44 & -0.10 \\
\hline
\end{tabular}

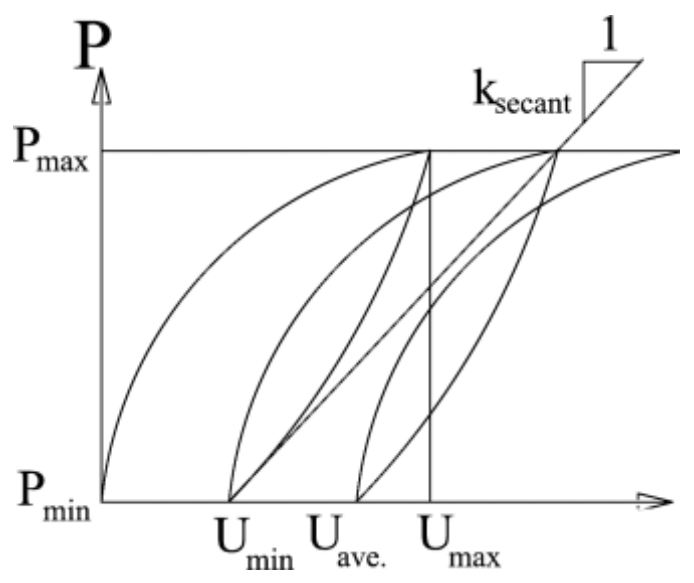

Figure 5. Schematic illustration of average deflection and secant stiffness.

minimum values of load and the deflection is found. From this the average deflection can be calculated as shown in equation 6 and the secant stiffness can be calculated as shown in equation 7 .

$U_{\text {average }}=\frac{U_{\max }+U_{\min }}{2}$
$K_{\text {secant }}=\frac{P_{\max }-P_{\min }}{U_{\max }-U_{\min }}$

The best fit to the accumulation of deflection was done with a power fit as proposed by Long and Vanneste (1994), cf. equation 8.

$U_{\text {average }}(n)=u_{0} \cdot n^{\alpha}$

Here $u_{0}$ is the accumulated deflection at the first cycle and $\alpha$ is an empirical coefficient which controls the shape of the curve. $n$ is the number of cycles. The accumulated deflection for a given cycle is defined as the average value for the cycle. The values of the coefficient to the proposed formula can be seen in Table 5 . If interpretation method 1 is used the accumulation depends on the load characteristic. $\zeta_{c}$ is nearly constant for all the tests expect test on $d=40 \mathrm{~mm}$. It must therefore be expected to see a relation between $\zeta_{b}$ and the coefficient to the power fit. A linear relationship is assumed which leads to the following equations.

$u_{0}\left(\zeta_{b}\right)=0.0300 \cdot \zeta_{b}+0.0002$

$\alpha\left(\zeta_{b}\right)=0.3170 \cdot \zeta_{b}+0.1585$ 
Table 5. Empirical constant for accumulation of the deflection from the cyclic testing.

\begin{tabular}{lll}
\hline$d$ & $u_{0}$ & $\alpha$ \\
\hline 16 & 0.016 & 0.324 \\
22 & 0.015 & 0.315 \\
28 & 0.010 & 0.339 \\
34 & 0.015 & 0.245 \\
40 & 0.012 & 0.256 \\
\hline
\end{tabular}

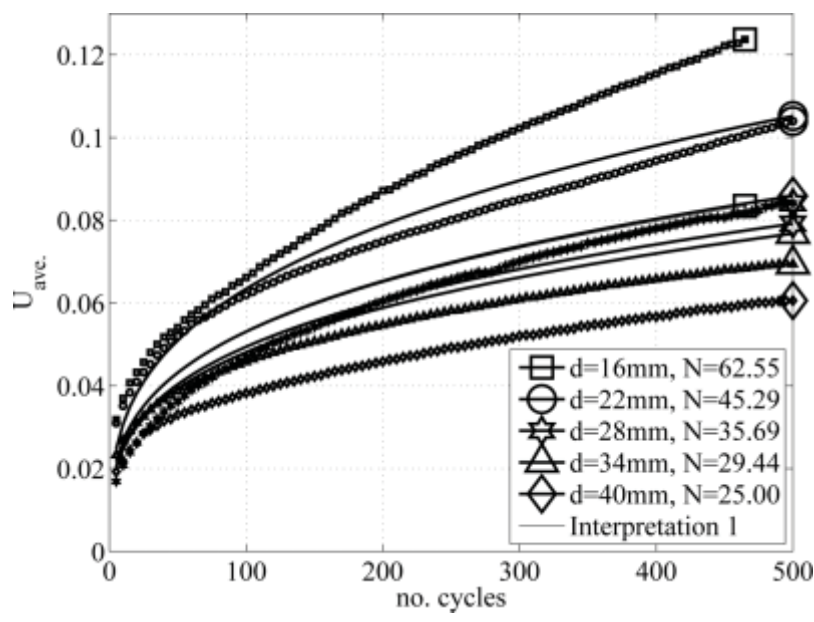

Figure 6. Accumulation of average deflection with interpretation method 1 prediction.

If on the other hand interpretation method 2 is used a linear relationship between the coefficients for the power fit and the scaling factor can be assumed. This leads to following equations.

$u_{0}(N)=0.0001 \cdot N+0.0096$

$\alpha(N)=0.0018 \cdot N+0.2266$

On figure 6 the accumulation of the deflection for cyclic testing is seen. Here is also shown the prediction as proposed in equation 8 for the interpretation methods 1 . The prediction for the interpretation methods 2 can be seen in Figure 7. None of the methods give good predictions, but it seems that interpretation method 2 is the best. It should again be noted that the cyclic loading is performed according to the maximum bearing capacity found from the monotonic tests. This means that the piles are not loaded to the same prototype loads. The maximum prototype load for the small pile with the large scaling factor is therefore larger than the large pile with the small scaling factor.

Lin and Liao (1999) proposed a logarithmic fit to the change in secant stiffness as shown in equation

$K_{\text {secant }}(n)=k_{0}+\kappa \cdot \ln (n)$

Here $k_{0}$ is the secant stiffness at the first cycle and $\kappa$ is an empirical coefficient which control the shape of the curve. $\mathrm{n}$ is the number of cycle. A formulation like

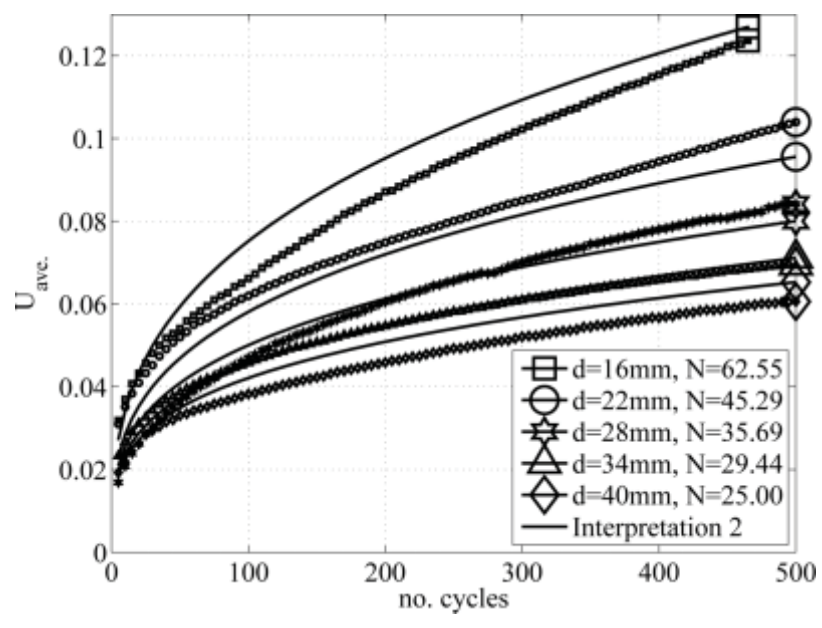

Figure 7. Accumulation of average deflection with interpretation method 2 prediction.

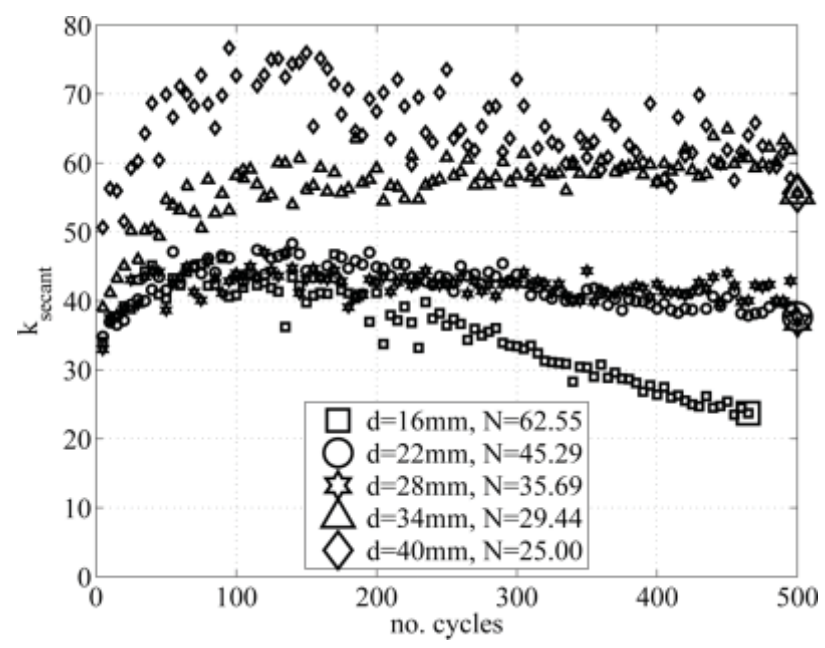

Figure 8. Change in secant stiffness.

this fits the first 100 cycles for the 5 cyclic tests, but as it can be seen in Figure 8 the secant stiffness starts to decrease or stabilize after 100 cycles. It has not been possible to fit the entire number of cycles cyclic. Looking at Figure 8 it can be seen that the secant stiffness is changing from test to test. The secant stiffness is large for the large piles and smaller for the small piles. The explanation for the difference can again be explained for interpretation method 1 as high $\zeta_{b}$ values gives small secant stiffness. Using method 2 high scaling factor gives high secant stiffness. No clear dependency is seen for the two interpretation methods.

\section{CONCLUSIONS}

A test series of modelling of models have been performed for both monotonic and cyclic loading. It has not been possible for the two loading types to reproduce exactly equal prototype response. The results have been analyzed in two ways; one as a normal scatter in the response, and one using a dependency of the scaling factor. It seems like the scaling factor affects the results but it is not clear. Nunez et al. (1988) reports 
also higher capacity for the small piles tested at high $\mathrm{g}$ levels and more tests have to be conducted. The fact that the piles in this test series are acting as stiff piles could be an explanation of the difference from previously modelling of models tests. More tests have to be conducted in order to clarify the scaling laws for these stiff laterally loaded piles.

\section{REFERENCES}

API (1993). Recommended Practice For Planning, Designing and Construction Fixed Offshore Platforms - Load and Resistance Factor Design. American Petroleum Institute.

Hansen, J. B. (1961). The ulitimate resistance of rigid piles against transversal forces. Danish Geotechnical Institute, Copenhagen, Denmark Bulletin NO. 12, 5-9.

Hoadley, P. J., Y. O. Barton, and R. H. G. Parry (1981). Cyclic lateral load on model pile i a centrifuge. In Proceedings of the Tenth International Conference on Soil Mechanics ans Foundation Engineering, Volume Vol. 1.

Langhaar, H. L. (1951). Dimensional analysis and theory of models. Technical report, John Wiley \& Sons.

LeBlanc, C. (2009). Design of Offshore Wind turbine Support Structures. Ph. D. thesis, Aalborg University.

Leth, C. T., A. Krogsbøll, and O. Hededal (2008). Centrifuge facilities at danish technical university. In 15th Nordic Geotechnical Meeting.

Lin, S. S. and J. C. Liao (1999). Permanent strains of piles in sand due to cyclic lateral loads. Journal of Geotech. and Geoenv. Engng. 125 No. 9, 798-802.
Long, J. H. and G. Vanneste (1994). Effects of cyclic lateral loads on piles in sand. Journal of Geotechnical Engineering 120, 225-244.

McClelland, B. and J. A. Focht (1958). Soil modulus for laterally loaded piles. Journal of the soil mechanics and foundations division-Proceedings of the American Society of Civil Engineers -, 1-22.

Nunez, I. L., P. J. Hoadley, M. F. Randolph, and J. M. Hulett (1988). Driving and tension loading of piles in sand on a centrifuge. In Centrifuge 88.

Poulos, H. and T. Hull (1989). The role of analytical geomechanics in foundation engineering. Foundation Engineering: Current principles and Practices, ASCE, Reston 2, 1578-1606.

Reese, L. C. and H. Matlock (1956). Non-dimensional solutions for laterally loaded piles with soil modulus assumed proportional to depth. Proceedings of the 8th Conference on Soil Mechanics -, 1-41.

Remaud, D., J. Garnier, and R. Frank (1998). Pieux sous charges lat'erales: étude de léffect de groupe. 5. Journées Nationales Génie Civil Génie Côtier, Toulon, pp. 369-376.

Stuit, H. G. (1995). Sand In The Geotehcnical Centrifuge. Ph. D. thesis, Technische Universiteit Delft.

Taylor, R. N. (1995). Centrifuges in modelling: principles and scale effects. Blackie Academic \& Professional.

Zhao, Y., K. Gafar, M. Elshafie, A. Deeks, J. Knappett, and S. Madabhushi (2006). Calibration and use of a new automatic sand pourer. In Physical modelling in Geotechnics, 6th ICPMG '06, pp. p. 265-270. 